\title{
A REPRESENTAÇÃo SOCIAL DA MÃE ACERCA DA CRIANÇA COM SÍNDROME DE DOWN*
}

\section{THE MOTHER'S REPRESENTATION OF THE CHILD WITH DOWN SYNDROME}

\author{
Cecília Helena de Siqueira Sigaud ** \\ Alberto Olavo Advincula Reis ***
}

SIGAUD, C.H. de S.; REIS, A.O.A. A representação social da mãe acerca da criança com Síndrome de Down. Rev.Esc.Enf.USP. , v.33, n.2, p. 148-56, jun. 1999.

RESUMO

Desenvolvido à luz da Teoria das Representações Sociais, o estudo buscou compreender a representação social da mãe acerca da criança com Sindrome de Down. Participaram nove mães, cujos filhos tinham idade escolar e freqüentavam um serviço especializado no municipio de São Paulo. Os dados, obtidos por entrevista semi-estruturada e individual, foram analisados por meio do método de análise de conteúdo, especificamente a análise temática. Os resultados apontaram para urna representação da criança na qual predominaram elementos negativos, levando a mãe a experimentar sentimentos ambivalentes em relação ao filho e comportar-se de modo superprotetor.

UNITERMOS: Sindrome de Down. Relações mãe-filho. Deficiência mental.

\section{ABSTRACT}

The present thesis was developed based on "The Social Representations Theory" and its purpose was to understand the mother's representation of the Down syndrome child. The subjects were nine mothers of Down syndrome patients between the ages of six and twelve, at a Sao Paulo specialized facility. The study material was obtained through semi-structured and individual interview, and examined by means of content analysis, particularly the thematic analysis. The results pointed to a maternal representation of the child with a predominance of negative components. Based on that perception the mother experienced ambivalent feelings and behaved in a overprotective way.

UNITERMS: Down Syndrome. Mother-child relations. Mental retardation.

\section{INTRODUÇÃO}

A motivação para este estudo partiu de nossa experiência junto a crianças com deficiência mental, quando tivemos oportunidade de observar que, muitas vezes, as mães demonstravam descrédito e frustração em reação ao filho, agindo de modo a perpetuar e até acentuar as limitações e incapacidades do mesmo, como ao realizar atividades que eles poderiam fazer por si.

Constata-se que as pessoas possuidoras de limitações, entre elas as portadoras de Sindrome de em nosso meio. Considerando que as atitudes e ações dos indivíduos são orientadas pelas representações que têm acerca dos fenômenos, conforme SPINK (1989), parte da problemática associada à questão da deficiência e dos indivíduos acometidos por ela decorre dessas representações existentes na sociedade, mais do que das limitações impostas por esta condição.

Assumindo que as crianças passam um tempo considerável de sua vida em família, sendo isto

Down, desfrutam de uma imagem bastante negativa

\footnotetext{
* Dissertação de Mestrado, orientada pelo Prof. Dr. Alberto Olavo Advíncula Reis e apresentada à Faculdade de Saúde Pública da Universidade de São Paulo (FSPUSP), São Paulo, 1997.

** Assistente do Departamento de Enfermagem Materno-Infantil e Psiquiátrica da Escola de Enfermagem da USP, enfermeira pediátrica e sanitarista, mestre em Saúde Pública, na área de Saúde Materno-Infantil, pela Faculdade de Saúde Pública da USP.

*** Professor Doutor do Departamento de Saúde Materno-Infantil da FSPUSP, psicólogo e doutor em Saúde Pública, na área de Saúde Materno-Infantil, pela FSPUSP.
} 
particularmente verdadeiro e mais acentuado para aquelas que apresentam Sindrome de Down, e que o desempenho infantil é influenciado em grande medida pelo ambiente imediato ao seu redor, objetivou-se na presente investigação compreender a representação da mãe acerca do filho limitado é de suma importância, pois esta estaria atuando de modo a restringir ou ampliar as oportunidades de desenvolvimento da criança, bem como as suas possibilidades de integração social. CHEVALLIER (1993) salienta que estudos sobre as representações sociais têm uma dupla finalidade: situar os indivíduos numa postura de disponibilidade interna em relação ao conhecimento e às habilidades para lidar com o problema e minimizar ao máximo as interferências negativas das representações nas atitudes e comportamentos deles.

\subsection{A pessoa com Sindrome de Down, à luz das ciências biomédicas e sociais}

Em 1866, John Langdon Down apresentou a primeira descrição das características da Sindrome de Down na literatura, explicando esta condição através da teoria da degenerecência racial. No final cia década de 1950, cientistas franceses descobriram que a mesma era resultado da trissomia do cromossomo 21 , caracterizada por acidente genético, de causa desconhecida (STRATFORD, 1994). Posteriormente, constatou-se que há associação entre idade avançada dos genitores e ocorrência do problema no feto, porém, até o presente momento, não há técnica curativa disponivel (LEFEVRE, 1981).

Sua incidência é elevada e, segundo STRATFORD (1994), acomete um em cada 600-700 nascidos vivos. De acordo com BATISTA et al. (1990), estima-se haver cerca de cem mil pessoas afetadas no Brasil, o que configura um problema de magnitude relevante no cenário nacional.

Os indivíduos portadores de Sindrome de Down têm expectativa de vida menor, devido à maior presença de anomalias orgânicas e ao incremento de doenças infecciosas no grupo (SIMILA et al., 1986). Possuem algumas características comuns, uma vez que todos apresentam um cromossomo 21 extra e este exerce influência na constituição fisica. Entretanto, PUESCHEL (1993) lembra que eles exibem também certa semelhança com seus pais, em função da herança transmitida pelo material genético.

Essa sindrome se manifesta com um atraso no desenvolvimento global do indivíduo afetado, tanto nas funções motoras como nas mentais, conforme afirmam BATISTA et al. (1990). 0 grau de comprometimento é bastante variável de pessoa para pessoa, assim como o de desempenho. A medida que as faculdades mentais vão assumindo importância na realização das atividades, começam a surgir maiores dificuldades (LEFEVRE, 1986).
Estudos revelam que todos os portadores de Sindrome de Down apresentam retardo mental, sendo a maioria entre os graus leves e moderado (PUESCHEL, 1993). Quanto à fala, o seu desenvolvimento é mais tardio e OLIVEIRA et al. (1992) apontam que eles compreendem acima do que são capazes de emitir, embora seu comprometimento persista até a idade adulta, tanto na recepção como na expressão da linguagem (KUMIN, 1994).

Os indivíduos afetados apresentam uma gama de variações de personalidade e temperamento similar aos demais, estando seu comportamento relacionado à qualidade do ambiente que os rodeiam (ROBINSON; ROBINSON, 1976).

Tendo em vista o exposto, é evidente que os portadores de Síndrome de Down são únicos, ou melhor, são distintos entre si em todos os aspectos, apresentando certas características que nada têm a ver com sua condição.

Indiscutivelmente, o indivíduo afetado guarda diferenças em relação aos outros. Contudo, em nossa sociedade, estas particularidades têm sido vistas como desvios ou anormalidades, que necessitam ser diagnosticadas e tratadas. Nesta perspectiva médica, de acordo com VELHO (1985), entende-se que o "mal" está localizado no indivíduo, enquanto fenômeno endógeno. E, neste sentido, o papel da sociedade é o de minimizar o mal existente, envidando esforços para "igualar" o deficiente aos não-deficientes.

Já na abordagem interacionista, o comportamento desviante é concebido enquanto produto social. Conforme BECKER (1977), os grupos sociais estabelecem regras, que definem situações sociais e tipos de comportamentos adequados a elas, constituindo-se em desvio a infração das mesmas. As pessoas que transgridem estas regras são vistas como desviantes e marginais. Assim sendo, o desvio não é uma qualidade do ato que a pessoa faz. Ele é conseqüência da aplicação de regras e sanções a um "transgressor", por outrem.

Nesta ótica, o individuo desviante não está fora de sua cultura, porém faz uma leitura divergente. Sua condição de desviante abrange parcialmente seu ser, havendo áreas em que se comporta como os demais e outras em que diverge dos valores dominantes

É preciso acabar com a ruptura entre o individuo e o social ou cultural, reconhecendo nos atos a marca do sócio-cultural. Seria positivo nos libertarmos dos aspectos unicausal e fatalista implicados pela postura organicista freqüentemente adotada hoje e considerarmos um conceito baseado em todos os aspectos, restabelecendo-se a integração entre as diferentes dimensões do comportamento humano. 
$\mathrm{Na}$ concepção atual acerca da deficiência, encontram-se elementos que têm suas raízes históricas no passado. Neste sentido, PERRON (1976) nos oferece uma sintese sobre a evolução histórica do pensamento e das atitudes face aos deficientes mentais, apontando quatro grandes periodos: antes de 1800, o problema inexistia do ponto de vista da ciência, prevalecendo visões sobrenaturais; entre 1800 e 1870, as primeiras experiências educativas dirigidas aos deficientes foram realizadas, envolvidas num clima humanitário e romântico; de 1870 a 1930-40, há expressões ostensivas de atitudes de medo e rejeição em relação à pessoa com deficiência; após a II Guerra Mundial até o presente, surge um novo direcionamento para o enfrentamento dos problemas de modo mais realista e otimista.

Passou-se da marginalização para o assistencialismo "oficialmente", e deste para a educação, reabilitação e integração social (AMARAL, 1995). Entretanto, este processo vem se dando de maneira não-linear, coexistindo posturas diversas e divergentes, que direcionam as práticas e politicas públicas em nosso país.

\section{PERCURSO METODOLÓGICO}

\subsection{Referencial teórico-metodológico}

Adotamos a Teoria das Representações Sociais, proposta por Moscovici, como referencial teóricometodológico deste trabalho de investigação, uma vez que ela nos permite compreender a maneira como as mães apreendem a criança portadora de Sindrome de Down e, em função disto, como elas se organizam e orientam suas ações em relação ao filho.

Conforme a definição oferecida por JODELET (1986), as representações sociais "constituem modalidades de pensamento prático, orientadas em direção à- comunicação, compreensão e dominio do meio social, material e ideal (imaginário)". Em sintese, as representações têm como propósito transformar algo estranho em familiar.

Segundo SPINK (1989), as representações sociais se definem por um conteúdo, composto de atitudes, imagens, opiniões e informações. Elas têm um caráter icônico (imagem) e simbólico (significado). Tais aspectos não podem ser separados, pois toda imagem está associada a um sentido e viceversa. Estel conteúdo se refere a algo (o objeto) e foi elaborado por alguém (o sujeito)

Desenvolvemos um estudo qualitativo, uma vez que o estudo das representações está voltado para o conteúdo das comunicações. De acordo com MINAYO (1992), as metodologias qualitativas são capazes de incorporar a questão do significado e da intencionalidade como inerentes aos atos, às relações e às estruturas sociais, sendo estas últimas construções humanas significativas. Têm como foco de atenção aquilo que é específico, particular, visando a compreensão do fenômeno estudado (MARTINS; BICUDO, 1989).

\subsection{Sujeitos e local do estudo}

Os sujeitos da pesquisa foram 9 mães de crianças portadoras de Síndrome de Down, em idade escolar (6 a 12 anos inclusive), que freqüentavam um serviço especializado no atendimento a crianças com deficiência mental, localizado no município de São Paulo.

\subsection{Obtenção dos discursos das mães}

Recorremos à técnica de entrevista para a coleta dos dados, uma vez que esta nos permite apreender o significado dado pela mãe à sua experiência pessoal junto ao filho com Sindrome de Down. No período de junho a setembro de 1995, foram realizadas, pelo próprio pesquisador, entrevistas individuais com técnica semiestruturada e não-diretiva, com o intuito de favorecer a livre expressão dos sujeitos e estimular a abordagem da temática em estudo. Para tanto, utilizou-se um roteiro abrangendo os seguintes tópicos: concepção de Sindrome de Down; características da criança quanto aos aspectos fisico, psicológico e de relacionamento interpessoal, de desempenho e social; expectativas e desejos maternos em relação ao filho; sentimentos e modo de agir da mãe junto à criança.

Ao início da conversa, colhemos algumas informações, visando caracterizar os sujeitos estudados quanto a sua situação familiar e sócioeconômica. Com o consentimento dos participantes, procedeu-se à gravação das falas, que foram transcritas posteriormente, respeitando-se com exatidão a maneira como cada um se expressou.

\subsection{0 método de análise dos dados}

Os dados de caracterização dos sujeitos foram planilhados, codificados e tabulados. O conjunto destas informações veio compor o perfil dos entrevistados, bem como cenário onde foram construídas as suas representações.

O material obtido nas entrevistas foi analisado segundo o. método de análise de conteúdo, comumente utilizado em pesquisas qualitativas (MINAYO, 1992). De acordo com BARDIN (1977), a análise de conteúdo é aplicável a qualquer comunicação e é definida como "um conjunto de técnicas de análise das comunicações visando obter, por procedimentos sistemáticos e objetivos de descrição do conteúdo das mensagens, indicadores 
(quantitativos ou não) que permitem a inferência de conhecimentos relativos às condições de produção/ recepção (variáveis inferidas) destas mensagens".

Entre as diversas técnicas de análise de conteúdo, optamos pela análise temática, uma vez que é habitualmente empregada nos estudos sobre motivações de opiniões, atitudes, valores, crenças (BARDIN, 1977 e FRANCO, 1986). Segundo MINAYO (1992), este tipo de análise consiste em descobrir os "núcleos de sentido" contidos nas comunicações, cuja presença ou freqüência tem algum significado.

\section{COMPREENDENDO O DISCURSO DAS MÃES}

\subsection{Cenário em que foram construidas as representações das mães}

Inicialmente, apresentamos algumas informações que nos permitem caracterizar as mães, quanto à sua composição familiar e situação de vida. A partir da análise deste material, podemos visualizar, ainda que parcialmente, o contexto de vida materno, onde foram elaboradas as suas representações acerca cio filho com Sindrome de Down.

No periodo em que foi desenvolvida a investigação, as idades maternas variaram amplamente (de 28 a 55 anos), predominando aquelas em idade acima de 35 anos, conforme era de se esperar dado que as crianças se encontravam na faixa etária escolar.

Observamos que a presença da criança deficiente não levou à ruptura do casal na maioria das famílias (8) que fizeram parte deste estudo. No único caso em que os pais viviam separados, a mãe atribuiu a dissolução do casal a não aceitação do filho com Sindrome de Down pelo pai, mas também ao fato deste último ter se mostrado uma pessoa violenta anteriormente.

Em relação à posição que a criança portadora de Sindrome de Down ocupa na prole, verificou-se que ela era o último (5) ou único filho (2) em sete das nove familias. Consideramos este dado bastante significativo, à medida que reflete o desejo dos pais não repetir tal experiência. Existem inúmeros trabalhos que exploram o impacto provocado pela existência de uma criança deficiente na família (OMOTE, 1980; ROMNEY, 1984; VASH, 1988; BATISTA et al., 1990; SIGAUD, 1994; AMARAL, 1995).

Constatamos que, embora a maioria das mães (7) trabalhassem, elas se ocupavam de atividades que ofereciam maior flexibilidade de horário, as quais podiam ser compatibilizadas com o cuidado dos filhos, segundo seu relato. Três delas estavam inseridas no mercado formal de trabalho. Apenas duas não desenvolviam atividade remunerada, restringindo-se ao âmbito da própria casa e família.

A realidade de trabalho feminino descrita acima é comumente encontrada em nossa sociedade, quando a mulher tem filhos, pois o cuidado dos mesmos costumeiramente recai sobre ela. Mas quando existe na prole uma criança deficiente, que freqüentemente se mostra mais dependente e demanda atenção em parte diferente das outras, a compatibilização destes afazeres com o trabalho se torna ainda mais dificil.

No que diz respeito ao nível sócio-econômico das famílias, em particular quanto à escolaridade materna e paterna, apenas uma familia contava com pais que tivessem nivel superior completo. Em outras duas, o casal tinha II Grau incompleto e nas demais (6), I Grau incompleto.

Em relação à ocupação do chefe da família, outro indicador sócio-econômico, a maioria deles (6) desempenhava atividades que gozavam de baixo prestígio social, segundo a Escala de Prestígio Ocupacional proposta por GOUVEIA (1970). Outro encontrava-se desempregado há quase um ano, realizando bicos eventuais, e apenas dois chefes de família realizavam funções de maior reconhecimento social.

No que toca à renda mensal per-capita das famílias, encontramos situações bastante diversas. A minoria (3) dispunha de menos de um salário mínimo por pessoa ao mês, ou seja, possuía menos que o menor valor estabelecido para garantir as necessidades de sobrevivência do indivíduo. Outras três contavam com uma renda superior a seis salários mínimos e ainda duas apresentavam um ganho mediano, entre 2 e 4 salários minimos percapita por mês.

Considerando duas variáveis mencionadas, ocupação do chefe e escolarização dos pais, observamos que predominaram famílias em condições de vida desfavoráveis. Quanto ao aspecto financeiro, um terço das mães e crianças pertenciam a famílias em condições desfavoráveis, outro terço vivia em situação satisfatória e o restante em posição mediana.

\subsection{Categorias de análise}

Passamos, então, à apresentação do esquema de categorias construído por nós. Os sub-temas que compõem as quatro principais categorias são destacados em negrito ao longo do texto. 
0 universo conceitual da sindrome de Down é dito pouco ou nada conhecido por algumas mães, embora a existência da criança tenha sido ressaltada como fonte de motivação para o aprendizado sobre esta questão. $\mathrm{O}$ seu conhecimento se restringe a certas características observáveis na pessoa portadora, conforme expomos adiante em outras categorias.

Para as mães que revelam possuir um conhecimento mais ampliado, o fenômeno Sindrome de Down é entendido enquanto doença orgânica, que acomete o material genético celular, cuja causa é desconhecida. Tal compreensão está de acordo com a perspectiva médica, que reduz o problema à patologia localizada no sujeito (fenômeno endógeno), estabelecendo uma dicotomia entre o fato individual e o social (VELHO, 1985).

É mencionada a existência de associação entre idade materna avançada e ocorrência do problema na criança. Porém apresentam-se dúvidas quanto à mesma, possivelmente, com a intenção de aliviar sentimento de culpa materno.

Observamos haver uma relação estreita entre o nivel de escolaridade materno e sua compreensão sobre o que vem a ser Síndrome de Down. Aquela que tem Grau Superior completo demonstra um maior e mais articulado entendimento sobre o problema do filho e outras duas que têm II Grau incompleto denotam ter assimilado alguns elementos do conhecimento científico sobre o tema, porém algo vago e não muito seguro.

Cabe salientar que nos processos de ancoragem e objetivação envolvidos na formação das representações, o conhecimento científico é deformado ao ser incorporado pelo senso comum. De acordo com Moscovici apud SA (1993), "representar unia coisa C..) não é com efeito simplesmente duplicá-la, repeti-la ou reproduzi-la; é. reconstituila, retocá-la, modificar-lhe o texto". Por esta razão, no universo representacional materno, encontram-se elementos modificados da ciência, ao lado de outros oriundos de campos do saber social, como o conhecimento popular e as tradições.

Prevalece uma concepção sobrenatural quanto à natureza da síndrome de Down, sendo imputada a existência do problema à vontade divina ou ao destino. Nesta ótica, originária do período medieval, a patologia é associada à idéia de prêmio ou castigo à mãe ou ao filho, e até compreendida como possessão demoníaca (PESSOTI, 1984).

Essas visões de caráter religioso e supersticioso evidenciam a necessidade das mães de atribuir a responsabilidade da ocorrência dofenômeno a algo ao alguém, aliviando-as de um
Por outro lado, há também o entendimento de uma das mães de que a Sindrome de Down é produto do acaso, incidindo na vida das famílias indiscriminadamente. Tal explicação é coerente com o enfoque da ciência, que propõe a gênese acidental da doença.

\section{Caracteristicas da Criança com Sindrome de Down}

A criança é definida enquanto diferente, sendo sua diferença percebida como de ordem qualitativa (competência distinta), e de ordem quantitativa (falha no funcionamento ou falta de capacidade). A diferença enquanto deficit transforma-se em desigualdade e, neste contexto, o diferente significa ser inferior.

O aspecto da diferença aparece abrangendo toda a extensão do ser e encobrindo os demais aspectos, que também o definem. A identidade infantil fica, desse modo, reduzida à sua diferença.

O filho é também apreendido como eterna criança, mantendo-se na condição infantil indefinidamente por impossibilidade de desenvolver papéis sociais do adulto. Neste sentido, TELFORD; SAWREY (1988.) atestam que a criança deficiente mental pode ser colocada permanentemente na posição de caçula da família, sem emergir de seu status infantil ou infantilizado.

É possivel que a criança com Sindrome de Down tenha potencialidades para ir além desta posição, mas que não o faça devido às restrições que lhe são impostas pela eficácia simbólica das representações daqueles que a cercam sob a égide da limitação.

\section{Caracteristicas Fisicas}

A aparência geral típica é destacada como peculiar à condição, identificando a criança como portadora de Síndrome de Down e, por esta razão, constituindo-se num fator estigmatizante da mesma. Tais características físicas são percebidas como imperfeições ou anormalidades decorrentes da patologia infantil.

A presença de sinais físicos visiveis, que diferenciam e, por isso, depreciam o sujeito (estigma), implica a maior ocorrência de reações de não-aceitação ou rejeição por parte das outras pessoas (GOFFMAN, 1988). DEXTER, em 1960, já dizia que, em nossa sociedade, papéis e status são designados .em algum grau com base na aparência do individuo, fazendo com que aquele que apresenta 
traços físicos que o tipificam como deficiente possivelmente apreende mais o papel de deficiente do que o que é considerado belo, mesmo que este último seja igualmente limitado.

Vê-se o filho como pessoa frágil no que diz respeito a aspecto da saúde, apresentando com maior freqüência agravos respiratórios e malformações congênitas principalmente. Esta noção de vulnerabilidade é atribuída à sua condição e torna a criança uma pessoa que requer cuidados mais freqüentes e prolongados.

\section{Características Psicológicas de Relacionamento Interpessoal}

A amabilidade, docilidade, obediência e sensibilidade são atributos percebidos como presentes de modo exacerbado e inerentes à Síndrome de Down. Estas características estão em concordância com as normas existentes para o convívio social e, por este motivo, são apreciadas e valorizados pelas mães e pela nossa sociedade de um modo em geral. Sendo tomada como representativa da criança, esta percepção traz satisfação às mães.

Desse modo, pode-se constatar que, quanto aos aspectos psicológicos e de relacionamento interpessoal, as crianças foram apreendidas positivamente.

\section{Características de Desempenho}

O filho é visto como quem apresenta um atraso no desenvolvimento, entendido enquanto comprometimento no ritmo, esperando-se que exiba comportamentos correspondentes a grupos etários mais jovens do que aquele em que se encontra. Contudo, há reconhecimento de seu potencial para a aquisição de novas habilidades e capacidades, embora com uma certa lentidão.

As mães reconhecem que o filho tem capacidade para desempenhar-se com desenvoltura e independência em diversas áreas. Entretanto, algumas agem de maneira muito solícita e outras descrevem situações compatíveis com expectativas de desempenho de crianças mais jovens.

As limitações de desempenho ocupam um lugar central na representação materna acerca da criança com Síndrome de Down. As restrições de desempenho foram encaradas como exclusividade da condição do filho, havendo generalização deste aspecto a todo seu ser e tornando-se definidor da identidade infantil. A Síndrome de Down passa a representar a totalidade do ser, cuja complexidade fica reduzida a um único traço, sendo desconsideradas as potencialidades da criança.
Cecília Helena de S. Sigaud, Alberto Olavo A. Reis

Observou-se estranhamento por parte das mães pelo fato da criança apresentar certas habilidades incomuns aos não-deficientes, como se fosse esperado que todos tivéssemos um padrão único de desempenho e que o filho afetado estivesse aquém deste em todos os aspectos. Nestes casos, a criança portadora de Síndrome de Down foi considerada superior, negando-se as suas limitações propriamente ditas.

Assim, identificamos a existência de uma visão bipolar quanto ao desempenho infantil: a criança é vista ora quase totalmente comprometida, ora superdotada, quando são ignoradas suas limitações. Nos dois extremos, o distanciamento das expectativas de desempenho aparece como tônica da representação materna acerca do filho

Foram destacadas limitações de desempenho em algumas áreas em especial, como a intelectual, a da comunicação e a do trabalho, persistindo os mesmos pontos de vista observados em relação às restrições de desempenho em geral.

A performance do filho na vida adulta é tomada como algo imprevisível e duvidosa, passível de ser desvendada somente quando chegar o momento. 0 desempenho incerto em relação ao futuro da criança, atrelado a outros fatores, causa às mães ansiedade e angústia.

As mães percebem o filho como alguém dependente, ou seja, que não dispõe de recursos próprios para prover a sua subsistência, requerendo, portanto, ser cuidado. Vale destacar que o que difere no caso da criança com Síndrome de Down são as características do cuidado demandado, que é referido como mais freqüente, de qualidade distinta e permanente indefinidamente.

A figura materna é apontada como a única em condições ideais para atender as necessidades infantis. Nesta perspectiva, o filho surge, então, como peso ou sobrecarga de trabalho para a mãe, uma vez que seu cuidado recai sobre ela e envolve grandes esforços para a sua satisfação. Esta percepção gera sentimentos de solidão e desamparo nas mulheres.

Identificamos no discurso das mulheres uma concepção idealizada sobre a maternidade, elemento este constituinte do pensamento social em nosso meio. BADINTER (1985) esclarece que a sociedade moderna ocidental atribui à mulher a principal responsabilidade pelo cuidado do filho, uma vez que ela seria dotada de condições ideais para tanto, devendo, portanto, curvar-se às leis da natureza. Neste contexto, as mulheres se sentem impelidas a exercerem o papel de mãe que lhes foi definido e designado e compartilham da idéia de que não podem se eximir desta função, independente das condições do filho e próprias. 
4 Respostas sociais perante à criança

Rejeição e marginalização aparecem enquanto as respostas mais comumente apresentadas pela sociedade quando diante da criança com Síndrome de Down, segundo a percepção materna. Esta postura social funciona impedindo-a de dividir o espaço freqüentado pelos outros, tais como escolas regulares e veículos de transporte coletivo, e mostram atitudes de indiferença e desinteresse.

Conforme AMARAL (1995), diante de algo ameaçador, os individuos podem regair de duas maneiras para se defender: ataque ou fuga. A primeira reação implicaria a destruição do objeto, um comportamento condenável em nossa cultura. Já a segunda opção, a fuga, é comumente adotada e aceita. sendo a rejeição e marginalização uma forma de expressão dela.

É possivel constatar a existência de idéias preconceituosas e atitudes de exclusão em relação à criança deficiente por parte das mães entrevistadas. Compreendemo-las como decorrentes do fato das mães estarem sujeitas aos mesmos fenômenos sócioafetivo-intelectuais que os demais individuos da sociedade, compartilhando, desse modo, das crenças e valores presentes em nosso meio.

\section{O Sentir Materno}

A experiência afetiva da mãe nos diz sobre sua atitude frente ao filho e, assim, revela-nos elementos que contribuem para ampliar nossa compreensão sobre a sua representação acerca da criança.

As mães relatam terem sofrido forte impacto emocional face ao conhecimento acerca da condição do filho, vivenciando uma situação de crise. A notícia teria significado para elas a perda do sonho de ser mãe de uma criança "perfeita" (criança idealizada). Assim, o contato com esta realidade provocou intensas emoções.

AMARAL (1995) aponta o "luto" materno, ou melhor, a "morte" do filho idealizado como parte essencial da experiência emocional de ter um filho deficiente. A presença de uma deficiência traz em seu bojo a vivência de perdas, que podem ser reais ou fantasiosas, presentes ou virtuais.

A ambivalência emocional constituiu-se $o$ padrão predominante de resposta afetiva das mães à criança afetada. Neste sentido, TELFORD; SAWREY (1988) lembram que, de um modo geral, os pais se sentem ambivalentes em relação aos filhos deficientes ou não, em função das responsabilidades e decepções comumente sofridas na experiência de criá-los. Sendo assim, eles amam e aceitam, bem como desgostam e rejeitam sua prole.
No caso da criança com Síndrome de Down, os sentimentos experimentados oscilam entre polaridades mais fortes. $\mathrm{O}$ afeto de amor expressado é justificado com base numa concepção idealizada de maternidade, a qual tem como principio a noção de "amor materno": toda mãe ama seu filho simplesmente porque o gerou. E o sentimento de ódio é absolutamente negado, sendo por isso mesmo significativo ao nosso ver. Parece-nos pouco provável que se possa nutrir apenas afeto de amor por alguém apreendido com características tão negativas.

Sendo o filho tomado enquanto ser limitado e dependente, cujos cuidados devem ser proporcionados idealmente pela mãe, temor e preocupação em relação à situação de vida da criança no futuro são referidos com muita freqüência e intensidade, principalmente relativos ao período após à morte materna. Freqüentemente, são mencionadas expectativas de futuro pessimistas, incluindo o desamparo e o abandono do indivíduo deficiente pelos familiares.

\section{O Agir Materno}

Analisando o comportamento materno junto ao filho, podemos conhecer suas atitudes e, conseqüentemente, aprofundar nossa compreensão acerca de sua representação.

Embora tenham afirmado que a criança com Sindrome de Down deve ser tratada indistintamente em beneficio dela mesma, as mães demonstram, em seus relatos, apresentar comportamento superprotetor muitas vezes, como quando prestam cuidados excessivos ou realizam tarefas que o filho teria condições de desincumbir-se sem ajuda. Tomamos tais comportamentos como indicativo da representação da criança enquanto ser limitado, frágil e dependente.

A superproteção seria, então, uma forma de compensação materna das carências e incapacidades infantis. Mas, vista por outro ângulo, ela se constituiria em tentativa de ocultar sentimentos hostis da mãe, que emergem diante das limitações do filho.

\section{CONSIDERAÇÕES FINAIS}

A representação materna acerca da criança com Síndrome de Down é composta predominantemente por elementos negativos. É evidente a ênfase dada às limitações infantis, enquanto traços centrais e marcantes que definem a pessoa deficiente e acabam por ocultar as suas demais características. Os efeitos limitadores específicos da patologia são generalizados a todas as áreas de atividade infantil, e a identidade da 
criança fica quase que totalmente restrita às limitações e incapacidades, que podem ser existentes em sua pessoa ou atribuidas a ela.

$\mathrm{Na}$ visão da mãe, a criança aparece ora quase totalmente destituída de potencialidades, ora enquanto ser superior. Há uma oscilação entre estes pontos opostos (visão bipolar), impossibilitando situar a criança em algum lugar intermediário entre os dois pelos.

Observamos, ao longo desta investigação, que a vivência materna junto ao filho com Síndrome de Down pouco contribuiu para a reformulação dos elementos presentes no pensamento social internalizados pela mãe. Neste sentido, AMARAL (1995) ressalta que .muitas das reações pessoais à deficiência., respondem freqüentemente mais ao imaginário coletivo que ao próprio universo interno".

Considerando o exposto, pensamos que a criança com Síndrome de Down continua sendo vitima desta representação social, que lhe é mais incapacitante e segregadora do que as próprias limitações inerentes à sua condição.

Não se trata de negar a deficiência e sim de aceitá-la, compreendê-la enquanto tal, sem contudo conferir-lhe um juizo social de valor. A criança com Síndrome de Down ou outra deficiência não é inferior ou anormal, é apenas possuidora de diferenças.

A deficiência deve ser enfrentada realisticamente, como também devem ser reconhecidas as potencialidades existentes na pessoa. A deficiência é, neste caso, parte da identidade infantil, mas não seu eixo.

Sobre esta questão, FÉDIDA (1984) afirma que "a negação da. deficiência, sob qualquer forma que seja, falsifica a relação com o outro, induz patologias relacionais crônicas e, sobretudo, caminha no sentido de formações relativas de caráter, que levam o Eu a suas próprias deformações". Quando uma criança pode verificar que é apreendida pelos pais com seu defeito, ela pode trabalhar tecnicamente com ele e evoluir.

\section{REFERÊNCIAS BIBLIOGRÁFICAS}

AMARAL, L. A. Conhecendo a deficiência em companhia de Hércules . São Paulo, Robe, 1995.

BADINTER. E. Um amor conquistado: o mito do amor materno. Rio de Janeiro. Nova Fronteira, 1985.

BARDIN, L. Análise de contcúdo. Lisboa, Edições 70, 1977.

BATISTA. D.A.S. et ai. Você sabe o que e Sindrome de Down? São Paulo. Projeto Down, 1990.

BECKER, H.S. Unia teoria da ação coletiva. Rio de Janeiro, Zahar. 1977.

CHEVALLIER, E. Importância do trabalho sobre as representações na formação dos agentes sanitários e' sociais. Rev. Bras. Crescimento Desenvol. Hum., v.3, n. 1, p.160-2, 1993.

DEXTER, L.A. Research on problems of mental subnormality. Am. J. Ment. Defic., v.64, p.835-8, 1960.

FÉDIDA, P. A negação da deficiência. In: D'ÁVILA NETO, M.I. (org.) A negação da deficiência: a instituição da diversidade. Rio de Janeiro, Achiamé/Socius, 1984. p.137-47.

FRANCO, M.L.P.B. O que é análise dc conteúdo. São Paulo, Pontifícia Universidade Católica de São Paulo, 1986. / Mimeografado/

GOFFMAN, E. Estigma: notas sobre a manipulação da identidade deteriorada. 4.ed. Rio de Janeiro, Guanabara, 1988.

GOUVEIA, A.J. Professorcs de amanhã: um estudo de escolha ocupacional. 2.ed. São Paulo, Pioneira, 1970.

JODELET, D. La representación social: fenómenos, concepto y teoria. In: MOSCOVICI, S. Psicologia social. Barcelona, Paidós, 1986. p.469-94.

KUMIN, L. Intelligibility of speech in children with Down syndrome in natural settings: parent's perspective. Percept. Mot. Skills, v.78, n.1, p.307-13, 1994.

LEFEVRE, B.H. Mongolismo: orientação para as famílias. 2.ed. São Paulo, ALMED, 1981

MARTINS, J.; BICUDO, M.A.V. A pesquisa qualitativa cm psicologia. São Paulo, Moraes/EDUC, 1989.

MINAYO, M.C. de S. O desafio do conhecimento: pesquisa qualitativa em saúde. São Paulo/Rio de Janeiro, HUCITEC/ ABRASCO, 1992.

OLIVEIRA, M.C.S. de et al. A Sindrome de Down e as dificuldades na fala. São Paulo, Projeto Down, 1992.

OMOTE, S. Reações de mães de deficicntes mentais ao reconhecimento da condição dos filhos afetados: um estudo psicológico. São Paulo, 1980. 125p. Dissertação (Mestrado)Instituto de Psicologia, Universidade de São Paulo.

PERRON, R. Atitudes e idéias face às deficiências mentais. In: ZAllO, R. et al. As debilidades mentais. Lisboa, Sociocultur, 1976. v.1, p.51-89

PESSOTTI, I. Deficiência mental: da superstição à ciência. São Paulo, TA Queiroz/EDUSP, 1984.

PUESCHEL, S. (org.) Sindrome de Down: guia para pais e educadores. Campinas, Papirus, 1993

ROBINSON, N.M.; ROBINSON, H.B. The mentally retarded child: a psychological approach. New York, McGraw-Hill, 1976.

ROMNEY, M.C. Congenital defects. implications on family development and parenting. Br. Med. J., v.293, n.6559, p.1395-7, 1984.

SA, C.P. de Representações sociais: o conceito e o estado atual da teoria. In: SPINK, M.J. (org.) O conhccimento no cotidiano: as representações sociais na perspectiva da psicologia social. São Paulo, Brasiliense, 1993. cap.1, p.19-45. 
SIGAUD. C.H. de S. A experiência da mãe de criança portadora de deficiência mental em fase do diagnóstico e início do tratamento. São Paulo, 1994. (Relatório final de pesquisa) - Escola de Enfermagem, Universidade de São Paulo.

SIMILA. S. et al. Mortality of mentally retarded children to 17 years of age assessed in a prospective one-year birth cohort. J. Ment. Defic. Res.. v.30, n.4, p.401-5. 1986.

SPINE. M.J. As representações sociais e sua aplicação em Pesquisa na Area da Saúde/Trabalho apresentado no 2. Congresso Brasileiro de Saúde Coletiva, São Paulo, 1989/.

STRATFORD, B. Down syndrome is for life. Int. J. Disabil., v.41, n.1, p.3-13, 1994.

TELFORD, C.W.; SAWREY, J.M. O individuo excepcional. 5.ed. Rio de Janeiro, Guanabara, 1988.

VASH, C.L. Enfrentando a deficiência: a manifestação, a psicologia, a reabilitação. São Paulo, EDUSP, 1988.

VELHO, G. O estudo do comportamento desviante: a contribuição da antropologia social. In: VELHO, G. Dcsvio e divergência: uma crítica da patologia social. 6.ed. Rio de Janeiro, Jorge Zahar, 1985. cap.1, p.11-28. 